\title{
REVIEW
}

\section{Corticosteroid treatment in sarcoidosis}

\author{
J.C. Grutters and J.M.M. van den Bosch
} ABSTRACT: At present there is no curative treatment for sarcoidosis. Immunosuppressive and/or
immunomodulatory drugs can, however, be used for controlling the disease.

Corticosteroids remain the mainstay of therapy. They function by suppressing the proinflammatory cytokines and chemokines that are involved in cell-mediated immune responses and granuloma formation. Only in a select group of patients is it justifiable to use these drugs, after careful evaluation of the pros and cons. Importantly, disease severity, e.g. threatened organ functions, and not disease activity itself should be the deciding factor in this process.

In the case of parenchymal involvement, there is substantial evidence that corticosteroids can improve respiratory symptoms and chest radiography and lung function parameters over 624 months. Other generally acknowledged (empirical) criteria for systemic treatment include neurological, cardiac and sight-threatening ocular involvement and hypercalcaemia. Remarkably, despite $>\mathbf{5 0}$ yrs of use, there is no proof of long-term (survival) benefit from corticosteroid treatment. In addition, there are still no data regarding the optimal dose and duration of corticosteroid or other immunosuppressive therapy.

One of the weightiest questions remaining is whether or not these drugs can prevent scarring in patients with a fibrogenic phenotype. As new agents, including infliximab and thalidomide, enter the stage and new diagnostic tools are now available, there is clearly a momentum to design multicentric randomised controlled trials with long enough follow-up ( $>5 \mathrm{yrs}$ ) to answer this pivotal question.

KEYWORDS: Corticosteroids, sarcoidosis, treatment

0 arcoidosis remains an enigmatic disease with extreme variability in organ involvement, extent and severity of granulomatous inflammation and fibrosis, and long-term outcome. Diagnosis is based on a compatible clinical presentation, supportive histological evidence of noncaseating granulomas and reasonable exclusion of other granulomatous diseases [1]. Since the beginning of the 1950s, corticosteroids have been widely used in the treatment of this disorder.

Although steroids and other immunosuppressive/immunomodulatory drugs are clearly an effective therapy in many cases, these are not curative treatment regimens, since relapses frequently occur after tapering of drugs [2]. This therapy is further complicated by the many potential side-effects that only justify its initiation when the potential benefits outweigh the risks. Herein lays a major problem, since only limited data exist for evidence-based decision-making. The present article gives an update on the available randomised controlled trials on corticosteroid treatment in sarcoidosis, summarises the currently accepted criteria from the literature and provides the authors' perspective on the subject.

\section{BASIC CONSIDERATIONS}

A number of considerations are currently fundamental to the understanding of sarcoidosis: 1) the disease is defined by the presence of granulomas, rarely with caseation but often with fibrinoid necrosis [3]; 2) sites of granulomatous inflammation contain variable numbers of activated T-cells and cells from the monocyte/macrophage lineage $[4,5]$; 3) these T-cells, macrophages and other local tissue cells express many pro-inflammatory cytokines and chemokines that have been shown experimentally to be critical in cell-mediated immune responses and granuloma formation, with a role for transforming growth factor- $\beta$ in spontaneous resolution of granulomas [6-8]; 4) sarcoidosis is associated with a T-helper cell type 1 immune response, at least in the initial years of disease [9]; 5) T-cell expansion is oligoclonal, consistent with an antigen-driven immune response $[10,11]$; 6) multiple aetiological agents

\section{AFFILIATIONS}

Heart Lung Centre Utrecht, Dept of Pulmonology, St Antonius Hospital, Nieuwegein, the Netherlands.

CORRESPONDENCE

J.C. Grutters

Heart Lung Centre Utrecht

Dept of Pulmonology

St Antonius Hospital

Koekoekslaan 1

3435 CM Nieuwegein

The Netherlands

Fax: 31306052001

E-mail: j.grutters@antonius.net

Received:

September 102005

Accepted after revision:

April 042006 
have been suggested to initiate this response, e.g. exposure to specific microorganisms such as Propionibacterium acnes, but no causation has been established to date [12]; 7) recently, evidence has been found for a loss of immunoregulation by CD1d-restricted natural killer T-cells and a genetically determined dysfunction of a putative co-stimulatory molecule (butyrophilin-like protein 2) [13, 14]; and 8) Löfgren's syndrome, the subset of sarcoidosis with the best prognosis, is associated with the formation of circulating immune complexes and specific human leukocyte antigen and nonhuman leukocyte antigen genotypes essentially $100 \%$ of the time [15-17]. These scientific findings are central to current concepts of the nature of sarcoidosis, and provide a framework in treatment discussions.

\section{CLINICAL CONSIDERATIONS}

There are some general principles of sarcoidosis, originating from decades of clinical observation, that should also be considered in the context of disease treatment [18, 19]. First, granuloma formation dictates the clinical course and therapeutic response, and, therefore, suppression of granuloma formation results in preservation of organ function. Secondly, fibrosis in sarcoidosis is probably not an independent process but progresses as a result of ongoing inflammation and tissue injury in combination with wound healing properties [19, 20]. Thus suppression of granuloma formation is also thought to minimise long-term fibrotic changes. Thirdly, in most patients, steroids are effective in suppressing granuloma formation in the short as well as the long term; other immunosuppressive therapy is variously effective, and selection of specific drugs has been largely empirical. Fourthly, there is usually a threshold level of drug effect for most patients, below which there is progression of granuloma formation and above which there is suppression, with improvement or stabilisation of organ function. Fifthly, the kinetics of granuloma formation are variable for an individual patient, with some patients progressing very slowly and others showing rapid progression of inflammation and organ dysfunction. Finally, different tissues involved in sarcoidosis inflammation appear to respond differently to different immunosuppressive or immunomodulatory drugs. For example, antimalarial drugs (e.g. hydroxychloroquine) appear more effective in treating skin and mucosal disease than pulmonary disease [19]. Although there is clearly a lack of understanding of the basic mechanisms involved in these clinical observations, they remain pertinent to treatment decisions in sarcoidosis.

\section{MECHANISM OF ACTION OF CORTICOSTEROIDS}

Glucocorticoids are very potent and effective drugs in preventing and suppressing inflammation caused by mechanical, chemical, infectious and immunological stimuli. They act mainly by repression of inflammatory genes, e.g. interleukin (IL)- 1 and tumour necrosis factor (TNF)- $\alpha$, adhesion molecules and receptors, and partly by induction of antiinflammatory genes, such as IL-1 receptor antagonist. In sarcoidosis, corticosteroids have been shown to restore the balance between locally produced type- 1 and type- 2 T-helper cell cytokines [21].

Corticosteroid resistance, however, has also been described in sarcoidosis patients, and is characterised by exaggerated
TNF- $\alpha$ release by alveolar macrophages compared to that found in patients showing favourable responses to steroids [22]. This finding suggests that steroid-refractory disease might benefit from treatment with anti-TNF- $\alpha$ antibody, i.e. infliximab [22].

Molecularly, corticosteroids act by binding to a cytosolic glucocorticoid receptor, which upon binding is activated and rapidly translocates to the nucleus. Within the nucleus, the glucocorticoid receptor either induces gene transcription by binding to specific DNA elements within the promoter/ enhancer regions of responsive genes or reduces gene transcription by interaction with pro-inflammatory transcription factors, such as activation protein -1 and nuclear factor- $\kappa B$ $(\mathrm{NF}-\kappa \mathrm{B})$. Increased expression of NF- $\kappa \mathrm{B}$ has recently been linked to the pathogenesis of sarcoidosis [23, 24]. Furthermore,

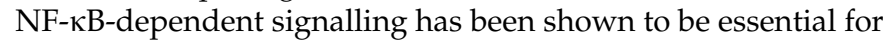
TNF- $\alpha$ and IL-6 production by alveolar macrophages and interferon gamma production by alveolar T-cells in patients with sarcoidosis [25]. Together, 10-100 genes are thought to be directly or indirectly regulated by glucocorticoids [26].

\section{STEROID TREATMENT IN SARCOIDOSIS}

As indicated, the clinical expression, natural history and prognosis of sarcoidosis are highly variable, with a tendency to wax and wane, either spontaneously or in response to therapy. Spontaneous remissions occur in nearly two-thirds of patients, but the course is chronic or progressive in the remainder [1]. Serious extrapulmonary involvement, e.g. cardiac, central nervous system and hepatic, occurs in $4-7 \%$ of patients on presentation, but this incidence increases as the disease progresses and depends strongly upon ethnicity [1]. Fatalities occur in $1-5 \%$ of patients, typically owing to progressive respiratory insufficiency or myocardial or central nervous system involvement [1]. Owing to the highly variable course of the disease, the fact that the majority of patients undergo spontaneous remission, and that severe complications and fatalities are relatively rare in white Europeans (but more common in other ethnic groups), there is no single criterion for systemic therapy in sarcoidosis. The pulmonary and extrapulmonary symptoms and/or findings that are currently regarded an indication for corticosteroid therapy are discussed below, with emphasis on the available scientific evidence.

\section{Pulmonary disease}

Mediastinal and hilar lymph nodes are almost invariably involved in sarcoidosis, but rarely cause specific symptomatology or functional impairment. Parenchymal lung disease is the second-most-frequent manifestation of pulmonary sarcoidosis and is strongly associated with respiratory symptoms and/or clinically significant impairment of lung function. In some cases, however, there is a remarkable discrepancy between the extent of parenchymal changes on chest radiography or high-resolution computed tomography and the degree of respiratory symptoms and/or lung function impairment. Importantly, prognosis is closely associated with pulmonary status [1].

Many uncontrolled studies have investigated oral corticosteroid therapy in pulmonary sarcoidosis, and have shown quite conclusively that these drugs can suppress granulomatous inflammation and are clinically effective [27-29]. However, a 
recent systematic Cochrane review (updated on February 17, 2005) identified only six randomised controlled trials on oral corticosteroid therapy for pulmonary sarcoidosis in PubMed, EMBASE and the Cochrane Central Register of Controlled Trials (CENTRAL); a summary of each is given in table 1 [27, 30-36]. From these trials, it can be concluded that oral corticosteroids significantly improve symptoms, biochemical markers, lung function and chest radiography results over 324 months of treatment. These benefits are particularly the case for patients with evidence of parenchymal disease on chest radiography (odds ratio 2.54) [37]. In this group, meta-analysis of randomised controlled lung function data showed a weighted mean difference for vital capacity of $4.2 \%$ of the predicted value (95\% confidence interval (CI) $0.4-7.9 \%$ pred), and a weighted mean difference for diffusing capacity of the lung for carbon monoxide of $5.7 \%$ pred (95\% CI $1.0-10.5 \%$ pred) [37]. Unfortunately, the studies provide almost no conclusive data on the long-term effects of corticosteroid treatment in sarcoidosis. Therefore, the key question yet to be answered remains whether or not steroids can slow down or prevent long-term development of irreversible pulmonary damage, i.e. development of lung fibrosis, and thus might have a beneficial effect on survival.

A number of studies have purported to answer this question but lacked sufficient methodological quality. One of these studies was initiated by the British Thoracic Society and included 149 sarcoidosis patients presenting with parenchymal abnormalities on chest radiography [38]. During an initial period of 6 months of observation, 33 patients received prednisone therapy for troublesome symptoms and 58 showed spontaneous radiographic improvement [38]. The remaining 58 patients were then allocated to either 18 months of corticosteroids (1 month at $30 \mathrm{mg} \cdot$ day $^{-1}, 1$ month at $20 \mathrm{mg} \cdot$ day $^{-1}$, 1 month at $15 \mathrm{mg} \cdot$ day $^{-1}$ and 9 months at
$10 \mathrm{mg} \cdot$ day $^{-1}$, followed by 6 months of tapering) or observation. The patients routinely given corticosteroids showed significantly improved lung function compared with the observation group (adjusted difference of $\sim 10 \%$ for both forced expiratory volume in one second and vital capacity) 5 yrs after the start of the treatment period. For the observation group, $\sim 20 \%$ of the patients progressed and still needed corticosteroid treatment. Importantly, the observation group also tended to exhibit a higher fibrotic score at final assessment, but this did not reach significance, which might have been related to coincidental imbalance of this score on allocation [38].

A further study that handled the long-term effects of corticosteroids is a large meta-analysis by REICH [39] that investigated the mortality of intrathoracic sarcoidosis patients in referral (2,838 cases) versus population-based settings (e.g. health maintenance organisations and government clinics in Scandinavian countries; 812 cases). It showed that sarcoidosis mortality was $4.8 \%$ in referral settings compared with $0.5 \%$ in population-based settings, and that this disparity was unlikely to be caused by adverse selection (such as stage or ethnicity) alone. Patients from referral centres received corticosteroids at seven times the frequency of those from population-based settings. It is of note that this provision was shown to be highly correlated with stage-normalised mortality, suggesting that excessive employment of corticosteroids might have an unfavourable influence on long-term outcome in some individuals. However, the study was hampered by major limitations, i.e. the absence of information on stage-independent disease severity variables and no specific data on mortality among corticosteroid recipients in the two settings, making definite conclusions impossible.

However, taking for granted the limitations of this and other studies, it is patently obvious that randomised controlled trials

TABLE 1 Randomised controlled trials of oral corticosteroid treatment in pulmonary sarcoidosis

\begin{tabular}{|c|c|c|c|c|}
\hline First author [Ref.] & $\begin{array}{c}\text { Treatment/control } \\
\mathbf{n}\end{array}$ & $\begin{array}{l}\text { Treatment, follow-up } \\
\text { months }\end{array}$ & Outcomes & Comments \\
\hline ISRAEL [31] & $\begin{array}{l}41 \text { prednisolone }\left(15 \mathrm{mg} \cdot \text { day }^{-1}\right) / \\
42 \text { placebo }\end{array}$ & $3,12-132$ (mean 60) & No difference & $\begin{array}{c}24 \% \text { of treatment and } 38 \% \text { of placebo group } \\
\text { showed relapse or progression of disease } \\
\text { during follow-up }\end{array}$ \\
\hline Selroos [27] & $\begin{array}{l}19 \text { methylprednisolone } \\
\left(32-4 \mathrm{mg} \cdot \text { day }^{-1}\right) / 18 \text { no treatment }\end{array}$ & 7,48 & $\begin{array}{l}\text { Improvement of } \mathrm{CXR}, \mathrm{VC} \text { and } \mathrm{DL}, \mathrm{CO} \text { at } \\
7 \text { months; no difference at later } \\
\text { follow-up }\end{array}$ & $\sim 30 \%$ of patients were lost to follow-up \\
\hline ZAKI [33] & $\begin{array}{l}77 \text { prednisone }\left(40-20 \mathrm{mg} \cdot \text { day }^{-1}\right) / \\
57 \text { placebo }\end{array}$ & $24, \geqslant 36$ & No difference & $\begin{array}{c}\text { Many patients lost to follow-up; no data } \\
\text { reported }\end{array}$ \\
\hline
\end{tabular}

Decreasing dose ranges represent dose tapering. CXR: chest radiography; VC: vital capacity; DL,CO: diffusing capacity of the lung for carbon monoxide; SACE: serum angiotensin-converting enzyme. ${ }^{*}$ : followed by inhaled budesonide $\left(800 \mu \mathrm{g} \cdot\right.$ day $\left.^{-1}\right)$ for 15 months. 
are needed, with a high degree of disease phenotyping and many years of follow-up, to answer one of the most weighty questions in sarcoidosis research, namely whether or not corticosteroids and/or other anti-inflammatory drugs really can prevent lung fibrosis in patients with a fibrogenic phenotype and improve survival.

\section{Inhaled corticosteroids}

As pulmonary sarcoidosis is a disease in which the pathological processes are distributed along lymphatic pathways, particularly those around the bronchovascular bundles, delivery of corticosteroids by the inhaled route is an attractive option. Moreover, inhaled corticosteroids have a low frequency of side-effects.

Uncontrolled clinical trials have indicated that inhaled steroids may favourably influence the course of acute pulmonary sarcoidosis in selected patients [40,41], an impression that has been confirmed in placebo-controlled pilot studies [42, 43]. Subsequently there have been six randomised controlled trials on inhaled corticosteroid therapy for pulmonary sarcoidosis (table 2) [36]. Four of these studies did not show an objective benefit of inhaled corticosteroids [44-47]. In the largest randomised controlled trial, however, AlBERTS et al. [48] found a significant improvement in symptom scores and inspiratory vital capacity, but not in serum angiotensin-converting enzyme levels, diffusion capacity of the lung for carbon monoxide or chest radiographic appearance, after 6 months of treatment. It is of note that this study was the only one that included only newly diagnosed steroid-naive patients.

Given the wide phenotypic variation in sarcoidosis, neither of the randomised controlled trials on inhaled steroids has been large enough to detect differences between subgroups of patients, e.g. those with an obstructive versus restrictive pattern of disease, nor have they specifically focussed on subjects with bronchial hyperreactivity. Bronchial hyperresponsiveness is a frequent finding in pulmonary sarcoidosis (up to $20 \%$ of cases) and is associated with the presence of microscopic nonnecrotising granulomas in the endobronchial mucosa [49-51]. Therefore, at present, the possibility cannot be excluded that a subgroup of patients, especially those with cough as a major symptom, may benefit from this therapy [52].

\section{Extrapulmonary disease}

In addition to the lungs, granulomas can occur in virtually any part of the body. Given that frequencies of extrapulmonary localisation of sarcoidosis vary considerably, especially depending on the ethnic background of the study population, many sites of extrapulmonary granuloma formation are probably underdiagnosed because they are often silent and without any functional consequences. Also, current diagnostic tools may not always detect small lesions and/or sites of diffuse mononuclear cell infiltration.

In addition, some extrapulmonary manifestations of sarcoidosis cannot be or can only indirectly be attributed to localised granuloma formation. A well-known example is hypercalcaemia, which is due to dysregulated production of $1,25-(\mathrm{OH})_{2} \mathrm{D}_{3}$ (calcitriol) by activated macrophages and granulomas [53]. Another not yet mechanistically clarified manifestation is small-fibre neuropathy. This neurological complication of sarcoidosis has been associated with a loss of intra-epidermal nerve fibres without co-localisation of mononuclear cell infiltration or granulomas [54]. Autoimmune diseases, e.g. thyroid disease and vitiligo, are another intriguing and commonly $(\sim 20 \%)$ seen complication in sarcoidosis patients [55]. Besides hypercalcaemia, disease manifestations such as small-fibre neuropathy, which are not directly related to granulomatous inflammation, are difficult to improve with steroids or other immunosuppressive drugs.

However, a few extrapulmonary localisations of sarcoidosis that are potentially life-threatening or cause severe functional deterioration of the affected organ are known to respond to systemic corticosteroid treatment.

TABLE 2 Randomised controlled trials of inhaled corticosteroid treatment in pulmonary sarcoidosis

\begin{tabular}{|c|c|c|c|c|}
\hline First author [Ref.] & $\begin{array}{c}\text { Treatment/control } \\
\mathbf{n}\end{array}$ & $\begin{array}{l}\text { Treatment, follow-up } \\
\text { months }\end{array}$ & Outcomes & Comments \\
\hline MILMAN [44] & $\begin{array}{c}9 \text { budesonide }(1200 \mu \mathrm{g} \text { daily }) / 12 \\
\text { placebo }\end{array}$ & 12,6 & No difference & $\begin{array}{l}\sim 40 \% \text { of the study population received oral } \\
\text { corticosteroids }\end{array}$ \\
\hline McGrath [46] & $\begin{array}{c}15 \text { beclometasone }(1600 \mu \mathrm{g} \\
\text { daily)/12 placebo }\end{array}$ & 6,0 & No difference & No data on oral corticosteroid use reported \\
\hline BAUGHMAN [47] & $\begin{array}{l}10 \text { fluticasone }(1600 \mu \mathrm{g} \text { daily }) / 11 \\
\text { placebo }\end{array}$ & 12,0 & No difference & $\begin{array}{l}\text { All patients received prednisone } 20 \mathrm{mg} \cdot \text { day }^{-1} \text { in } \\
\text { the } 4 \text { weeks before study entry }\end{array}$ \\
\hline ALBERTS [48] & $\begin{array}{l}22 \text { budesonide }(1200 \mu \mathrm{g} \text { daily }) / \\
25 \text { placebo }\end{array}$ & 6,6 & $\begin{array}{l}\text { Improvement in symptom score and } \\
\qquad \mathrm{VCl}(\sim 8 \%)\end{array}$ & Newly diagnosed steroid-naive patients \\
\hline
\end{tabular}

BALF: bronchoalveolar lavage fluid; VCI: inspiratory vital capacity. 


\section{Cardiac sarcoidosis}

Cardiac localisation of granulomas is probably more common than is presently thought. As it is one of the leading causes of death in sarcoidosis, every new patient should be carefully asked about cardiac symptoms and electrocardiography performed. Upon suspicion, further investigations should include adequate monitoring of arrhythmias and heart blocks and myocardial imaging [1]. At present, the guidelines of the Japanese Ministry of Health and Welfare are the only available guidelines for establishing the diagnosis [56].

Cardiac sarcoidosis is regarded an absolute indication for corticosteroid therapy. There is some evidence that steroids can suppress inflammation and progression of fibrosis leading to significant improvement in survival [57]. In addition, three recent retrospective studies with larger groups of patients have demonstrated a good prognosis in corticosteroid-treated patients [58-60]. Interestingly, it has been proposed that myocardial granulomas might respond better to corticosteroids than in other organs [61]. In addition, a discrepancy between cardiac and noncardiac manifestations of sarcoidosis can occur, i.e. pulmonary remission of granulomatous inflammation does not necessarily mean cardiac remission [62].

\section{Neurosarcoidosis}

Neurosarcoidosis shows a predilection for the base of the brain, but any part of the central or peripheral nervous system may be affected, including conditions such as cranial nerve palsies, granulomatous meningitis, hypothalamic and pituitary lesions, space-occupying masses, spinal cord involvement, progressive multifocal leukoencephalopathy and peripheral neuropathy [63]. Most of these conditions are regarded as absolute criteria for systemic corticosteroids [1]. However, hardly any good data exist concerning the efficacy of this treatment. In a nonrandomised study on neurosarcoidosis, ALLEN et al. [64] reported effectiveness of corticosteroids in 16 $(84 \%)$ cases of a series of 19 , but, in another series of 47 cases, more than half of the patients progressed despite corticosteroid and/or other immunosuppressive therapy [65]. It is of note that, in this last series of patients, a dose of prednisolone of $<20-25 \mathrm{mg} \cdot \mathrm{day}^{-1}$ was associated with recurrence of neurological symptoms [65].

\section{Ocular sarcoidosis}

Any part of the eye or orbit may be affected in sarcoidosis [66]. Uveitis is the most common of all sarcoid eye lesions [67, 68]. Acute anterior uveitis, although it may resolve without complications, should be treated with topical steroids and mydriatic eye drops in order to prevent adhesions between iris and lens (posterior synechia), glaucoma and cataract $[18,66]$. Posterior uveitis (with or without anterior uveitis, i.e. panuveitis) has a more chronic and severe course. It can lead to severe visual impairment caused by cystoid macular oedema, vitritis, choroidal granulomas, retinal vasculitis, and retinal and intravitreal haemorrhages [18, 69]. This condition requires peri/intraocular injections with corticosteroids and/or systemic therapy to control the inflammation and prevent (irreversible) loss of vision $[18,66]$. Other eye lesions include keratoconjunctivitis sicca, conjunctival folliculitis, lacrimal gland involvement, dacryocystitis, oculomotor nerve palsy (especially of the sixth cranial nerve, i.e. abducens nerve) and, rarely, optic nerve involvement [66]. Severe uveitis posterior and optic nerve involvement, especially, which are associated in a quarter of cases, are sight-threatening conditions and count as absolute criteria for high-dose steroids or other immunosuppressives [66].

\section{Various extrapulmonary complications}

Rarely, other extrapulmonary complications justify systemic treatment in sarcoidosis, e.g. cosmetically marring cutaneous disease and laryngeal or endobronchial disease with significant obstruction not responding to topical corticosteroids, severe joint manifestations, organ-threatening liver and kidney disease, symptomatic muscle involvement and symptomatic bone (marrow) localisation. In some of these instances, corticosteroids appear inferior to other immunosuppressive or immunomodulatory drugs [19]. However, no randomised controlled data are presently available for a well-founded statement.

\section{NONSTEROIDAL TREATMENT}

Various other immunosuppressive or immunomodulatory drugs can be used as a treatment in sarcoidosis. To date, these drugs have mainly been used as an alternative in refractory cases. On the basis of the available data on safety and efficacy, methotrexate, hydroxychloroquine and azathioprine are currently regarded as the preferred agents in pulmonary sarcoidosis [1, 70]. However, most of the published data is anecdotal, with observations made on small numbers of patients. A systematic Cochrane review on immunosuppressive and cytotoxic therapy for pulmonary sarcoidosis could identify only four randomised controlled trials comparing chloroquine [71, 72], cyclosporin A [73] and methotrexate [74, 75]. Data on symptoms, lung function and chest radiographic scores were largely inconclusive, and side-effects associated with some of the therapies were severe [75]. Recently, leflunomide, an analogue of methotrexate, has been shown to be effective in sarcoidosis, and might be an attractive alternative as it appears to show less pulmonary toxicity than methotrexate [76, 77].

Besides their use in alternative therapy in corticosteroidrefractory cases, methotrexate and azathioprine can also be used as a means of maintaining a low dose of steroids, i.e. as corticosteroid-sparing agents [74, 78]. This approach is of value in patients that respond well on prednisone but experience adverse effects when the drug needs to be given in a relatively high dose for a longer period.

As previously indicated, it should be taken into account that some extrapulmonary manifestations of sarcoidosis might respond better to specific nonsteroidal drugs. However, recommendations are largely based on experience rather than evidence. For example, methotrexate has been reported as especially useful in uveitis, and has recently been proposed as first-choice immunosuppressant in corticosteroid-resistant neurosarcoidosis $[79,80]$. The antimalarial drugs chloroquine and hydroxychloroquine (lower ocular toxicity than chloroquine) appear more effective in skin and mucosal than pulmonary disease [19]. Also, thalidomide might be especially effective in lupus pernio [81]. 
Finally, treatment with infliximab, a chimeric monoclonal antibody directed against soluble and membrane-bound TNF$\alpha$, a central cytokine in the pathogenesis of sarcoidosis, has recently proved effective in the treatment of refractory sarcoidosis $[82,83]$. In a series of seven cases of chronic ocular sarcoidosis, all responded to infliximab [84]. It is hoped that a large multicentric randomised controlled trial that is currently underway (sponsored by Centocor, Leiden, the Netherlands) will better determine the role of this drug in sarcoidosis treatment. However, it is of note that not all TNF- $\alpha$ blockers appear beneficial. Etanercept, a soluble TNF- $\alpha$ receptor construct, was found ineffective against pulmonary and chronic ocular sarcoidosis [85, 86]. Etanercept binds soluble TNF- $\alpha$ alone, whereas infliximab also binds to the membranebound form. Interestingly, VAN DEN BRANDE et al. [87] showed that infliximab but not etanercept induces apoptosis in lamina propria T-lymphocytes from patients with Crohn's disease.

\section{ATS/ERS/WASOG CRITERIA FOR TREATMENT}

The members of the committee of the joint statement on sarcoidosis of the American Thoracic Society (ATS), European Respiratory Society (ERS) and World Association of Sarcoidosis and Other Granulomatous Disorders (WASOG), as well as other sarcoidologists, found clear indications for the initiation of systemic corticosteroids in sarcoidosis in cases of life- or sight-threatening organ localisation, i.e. cardiac or central nervous disease, or ocular disease not responding to topical therapy [1, 18, 88-90]. These and other consensus indications for therapy are summarised in table 3.

One of the most conflicting situations generally encountered is that in which symptoms lag behind the radiographic progression of infiltrative lung disease, seen most frequently in white patients and rarely in African-American patients [18]. Although some sarcoidologists maintain that there is a risk in waiting until symptoms develop because irreversible fibrosis may develop, there is currently no consensus available in the literature $[18,91]$.

\section{THE AUTHORS' APPROACH}

The Heart Lung Center Utrecht is a national referral centre for sarcoidosis, which diagnoses sarcoidosis according to ATS/ ERS criteria [1]. Extrapulmonary disease is establised and managed in close collaboration with related specialists, e.g. there is a Cardiac Sarcoidosis Multidisciplinary Team that includes cardiologists, pulmonary physicians and nuclear medicine specialists and meets regularly.

\section{Decision to undertake corticosteroid therapy}

After diagnosis, all sarcoidosis patients are systematically evaluated for pulmonary and extrapulmonary organ involvement and functional consequences. The following questions are then central to the decision as to whether the initiation of corticosteroid and/or other immunosuppressive/immunomodulatory therapy is justified. 1) Are the symptoms related to sarcoidosis and is there a significant level of disability? 2) Which organs are involved and what is the functional consequence for each organ? 3) Is there evidence of active disease? 4) Are there signs of a fibrogenic phenotype? 5) Is the potential benefit likely to outweigh the risks of treatment? The criteria for treatment used at the St Antonius Hospital (Nieuwegein, the Netherlands) are given in table 4 .

The relative criteria in this table refer to a substantial subset of patients in whom there is no major organ involvement but an unacceptable reduction in quality of life due to disease activity, with symptoms such as cough, fatigue, heavy sweats, weight loss, arthralgia and disfiguring skin leasions. Although without present danger from the disease, systemic treatment might also be worth considering in these cases. However, decisionmaking should be dominated by the patient. The doctor's primary task is to inform the patient on the risks and benefits of corticosteroid treatment. A great deal of negotiation is required, and lower-dose treatment, at a level acceptable to the patient, may then sometimes be life-transforming. However, caution is needed when reduction in quality of life cannot be attributed to disease activity.

\section{Local protocol}

The local protocol involves 30-40 $\mathrm{mg}$ prednisone daily in a single dose, and is gradually reduced to a maintenance level of 7.5-10 mg over a period of 6 months (table 5). Higher doses of $1 \mathrm{mg} \cdot \mathrm{kg}$ body weight $^{-1}$ are given to control severe ocular, neurological and myocardial localisations. If a relapse occurs, as evidenced by reappearance of clinical signs, chest radiographic abnormalities or lung function impairment, prednisone levels are then increased to a dosage sufficient to control the disease and subsequently tapered to a maintenance dose that is likely to be higher than the dose at which the relapse occurred. It has been shown that almost all of these relapses occur within 1-2 months of steroid therapy withdrawal, and three-quarters of patients who require corticosteroids for $\geqslant 5$ yrs relapse when corticosteroids are withdrawn [92]. Of these patients, $>90 \%$ can be maintained on a regimen of $\leqslant 15 \mathrm{mg}$ prednisone daily, and $65 \%$ on $\leqslant 10 \mathrm{mg}$ [92]. Although

TABLE 3 American Thoracic Society/European Respiratory Society/World Association of Sarcoidosis and Other Granulomatous Disorders criteria for considering corticosteroid treatment in sarcoidosis

Progressive symptomatic pulmonary disease

Asymptomatic pulmonary disease with persistent infiltrates or progressive loss of lung function

Cardiac disease

Neurological disease

Eye disease not responding to topical therapy

Symptomatic hypercalcaemia

Other symptomatic/progressive extrapulmonary disease

From $[1,88]$ 


\section{TABLE 4 Criteria for corticosteroid treatment of sarcoidosis at St Antonius Hospital ${ }^{\#}$}

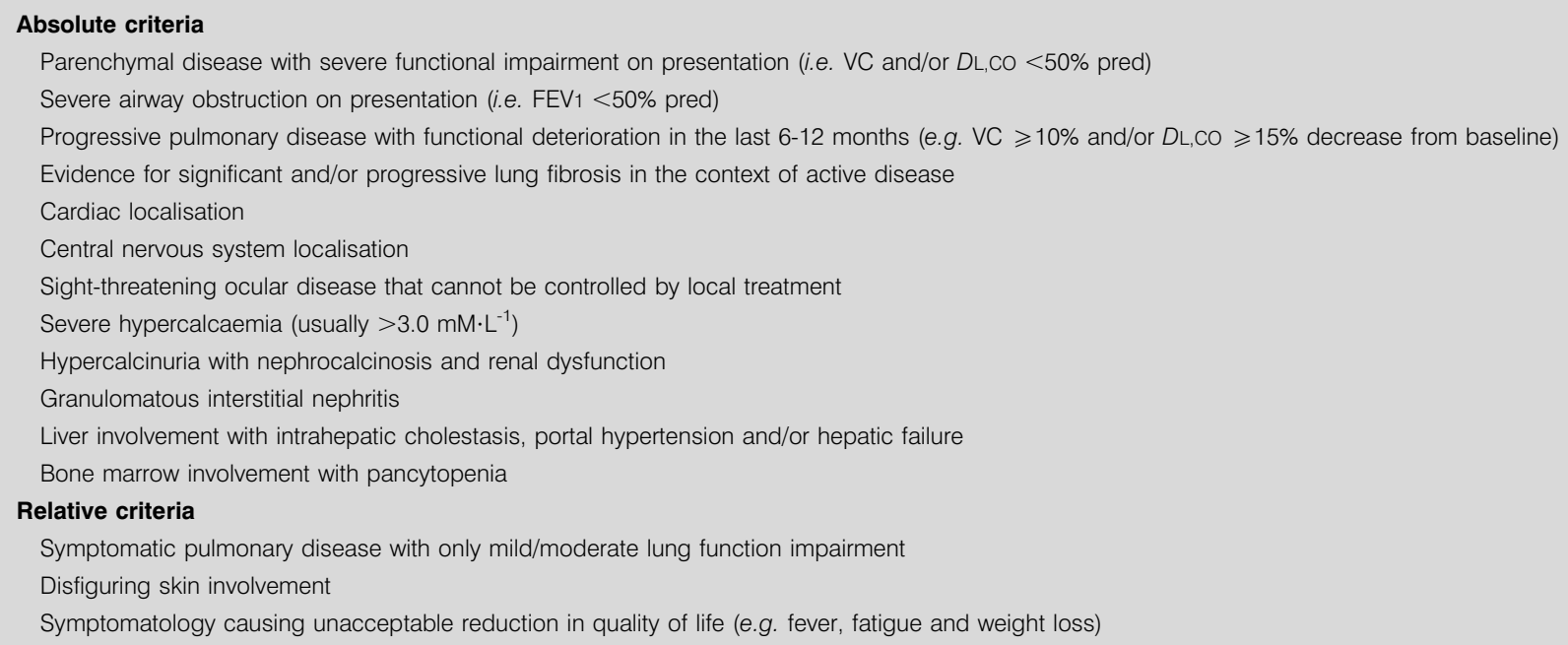

VC: vital capacity; DL,CO: diffusing capacity of the lung for carbon monoxide; FEV1: forced expiratory volume in one second; \% pred: percentage of predicted value. \#: Nieuwegein, the Netherlands.

an alternate-day regimen is effective, with considerable reduction in side-effects, daily treatment is recommended because of the increased compliance [93].

Alternative immunosuppressive treatment is considered in patients who fail to respond to corticosteroids or in whom a daily prednisone dose of $\geqslant 20 \mathrm{mg}$ is required for an effect. In these cases, methotrexate is given as the first-choice add-on therapy to control inflammation. In the present authors' experience, methotrexate is fairly effective and well tolerated in the majority of cases at a dosage of up to $15 \mathrm{mg} \cdot \mathrm{week}^{-1}$, although close monitoring of liver function is required. In those patients who cannot tolerate corticosteroid side-effects, methotrexate is given as a steroid-sparing agent, tapering prednisone to the lowest possible dose. If this approach fails,

\begin{tabular}{|c|c|c|}
\hline TABLE 5 & \multicolumn{2}{|c|}{$\begin{array}{l}\text { Dosing schedule for corticosteroid treatment of } \\
\text { sarcoidosis }^{\#} \text { at St Antonius Hospital }\end{array}$} \\
\hline \multirow{4}{*}{ Initial dosage ${ }^{+}$} & $\begin{array}{c}\text { Dose } \\
\mathrm{mg} \cdot \text { day }^{-1}\end{array}$ & $\begin{array}{c}\text { Duration } \\
\text { weeks }\end{array}$ \\
\hline & 40 & 4 \\
\hline & 30 & 4 \\
\hline & 20 & 4 \\
\hline \multirow{5}{*}{$\begin{array}{l}\text { 3-month evalu } \\
\text { response }^{\S}\end{array}$} & Iation of & \\
\hline & 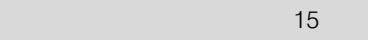 & 13 \\
\hline & 10 & 13 \\
\hline & 7.5 & 13 \\
\hline & Taper to 0 & $13-26$ \\
\hline \multicolumn{3}{|c|}{$\begin{array}{l}\text { \#: patients go through all of the different doses shown; }{ }^{~} \text { : Nieuwegein, the } \\
\text { Netherlands. }{ }^{+} \text {: often } 30-40 \mathrm{mg} \cdot \text { day }^{-1} \text { prednisone, i.e. } 0.5 \mathrm{mg} \cdot \mathrm{kg} \text { body weight }{ }^{-1} \text {, } \\
\text { higher doses of up to } 1 \mathrm{mg} \cdot \mathrm{kg} \text { body weight }{ }^{-1} \text { are used for cardiac sarcoidosis } \\
\text { or neurosarcoidosis; }{ }^{\mathrm{s}} \text { : if no response, consider irreversible, fibrotic disease, } \\
\text { noncompliance, inadequate dosage and intrinsic corticosteroid resistance; if } \\
\text { response, continue slow tapering. }\end{array}$} \\
\hline
\end{tabular}

the present authors currently consider infliximab as the next therapy, i.e. in patients with severe corticosteroid/methotrexate-refractory sarcoidosis and ongoing disease activity. In these cases, it is the authors' experience that a switch to drugs such as azathioprine or hydroxychloroquine provides hardly any benefit for the patient.

Osteoporosis prophylaxis is routinely used in sarcoidosis patients who need corticosteroid treatment for prolonged periods. Initiation of this prophylaxis as soon as possible after corticosteroid therapy commences might be of particular importance in this disease as it has been associated with increased bone turnover $[94,95]$. Special care must be taken if vitamin $\mathrm{D}$ or calcium is supplemented in patients with sarcoidosis because this disease may cause hypercalcinuria or hypercalcaemia by increased endogenous production of vitamin $\mathrm{D}$, with subsequent increases in calcium absorption in the intestine, resorption in the bones and excretion in the kidney [1, 96].

Finally, the present authors do not routinely use inhaled corticosteroids for pulmonary sarcoidosis. However, in the current authors' experience, some patients, especially those with marked bronchial hyperresponsiveness and symptoms of dry cough, experience great relief with this therapy. Also, in patients with macroscopic endobronchial abnormalities (e.g. bronchial stenosis and/or "cobblestones") or radiographic evidence of extensive bronchovascular distribution with an obstructive lung function pattern, inhalational therapy is given.

\section{CONCLUSIONS}

Systemic corticosteroids remain the first-choice therapy in organ- and/or life-threatening sarcoidosis. Although most criteria for treatment are empirical, there is reasonable evidence from randomised controlled trails that these drugs have a short-term effect in patients with (progressive) 
parenchymal disease on chest radiography and impaired lung function. In addition, it is generally accepted that severe nonpulmonary sarcoidosis, including sight-threatening ocular, cardiac and neurological involvement, should be treated systemically. However, no long-term benefits as regards outcome, i.e. prevention of lung fibrosis and improved survival, have yet been proven. Thus there is clearly a need for further well-designed studies, which will almost certainly need to be multicentric (international), addressing the continuing uncertainties regarding sarcoidosis treatment.

\section{REFERENCES}

1 American Thoracic Society, Statement on sarcoidosis. Am J Respir Crit Care Med 1999; 160: 736-755.

2 Sharma OP. Pulmonary sarcoidosis and corticosteroids. Am Rev Respir Dis 1993; 147: 1598-1600.

3 Popper HH. Epithelioid cell granulomatosis of the lung: new insights and concepts. Sarcoidosis Vasc Diffuse Lung Dis 1999; 16: 32-46.

4 Hunninghake GW, Crystal RG. Pulmonary sarcoidosis: a disorder mediated by excess helper T-lymphocyte activity at sites of disease activity. N Engl J Med 1981; 305: 429-434.

5 Yeager H Jr, Williams MC, Beekman JF, Bayly TC, Beaman BL. Sarcoidosis: analysis of cells obtained by bronchial lavage. Am Rev Respir Dis 1977; 116: 951-954.

6 Zissel G, Homolka J, Schlaak J, Schlaak M, MullerQuernheim J. Anti-inflammatory cytokine release by alveolar macrophages in pulmonary sarcoidosis. Am J Respir Crit Care Med 1996; 154: 713-719.

7 Agostini C, Semenzato G. Cytokines in sarcoidosis. Semin Respir Infect 1998; 13: 184-196.

8 Moller DR. Cells and cytokines involved in the pathogenesis of sarcoidosis. Sarcoidosis Vasc Diffuse Lung Dis 1999; 16: 24-31.

9 Moller DR, Forman JD, Liu MC, et al. Enhanced expression of IL-12 associated with Th1 cytokine profiles in active pulmonary sarcoidosis. J Immunol 1996; 156: 4952-4960.

10 Moller DR. Involvement of T cells and alterations in T cell receptors in sarcoidosis. Semin Respir Infect 1998; 13: 174-183.

11 Grunewald J, Janson CH, Eklund A, et al. Restricted V alpha 2.3 gene usage by $\mathrm{CD} 4+\mathrm{T}$ lymphocytes in bronchoalveolar lavage fluid from sarcoidosis patients correlates with HLA-DR3. Eur J Immunol 1992; 22: 129-135.

12 Newman LS. Aetiologies of sarcoidosis. Eur Respir Mon 2005; 32: 23-48.

13 Ho LP, Urban BC, Thickett DR, Davies RJ, McMichael AJ. Deficiency of a subset of T-cells with immunoregulatory properties in sarcoidosis. Lancet 2005; 365: 1062-1072.

14 Valentonyte $\mathrm{R}$, Hampe J, Huse $\mathrm{K}$, et al. Sarcoidosis is associated with a truncating splice site mutation in BTNL2. Nat Genet 2005; 37: 357-364.

15 Selroos O, Klockars M, Kekomaki R, Pentinen K, Lindstrom $\mathrm{P}$, Wager O. Circulating immune complexes in sarcoidosis. J Clin Lab Immunol 1980; 3: 129-132.

16 Grutters JC, Sato H, Welsh KI, du Bois RM. The importance of sarcoidosis genotype to lung phenotype. Am J Respir Cell Mol Biol 2003; 29: S59-S62.
17 Spagnolo P, Renzoni EA, Wells AU, et al. C-C chemokine receptor 2 and sarcoidosis: association with Lofgren's syndrome. Am J Respir Crit Care Med 2003; 168: 1162-1166.

18 Johns CJ, Michele TM. The clinical management of sarcoidosis. A 50-year experience at the Johns Hopkins Hospital. Medicine (Baltimore) 1999; 78: 65-111.

19 Möller DR. Treatment of sarcoidosis - from a basic science point of view. J Intern Med 2003; 253: 31-40.

20 Kruit A, Grutters JC, Ruven HJT, et al. TGF beta polymorphisms in sarcoidosis patients with and without pulmonary fibrosis. Sarcoidosis Vasc Diffuse Lung Dis 2005; 22: 253.

21 Milburn HJ, Poulter LW, Dilmec A, Cochrane GM, Kemeny DM. Corticosteroids restore the balance between locally produced Th1 and Th2 cytokines and immunoglobulin isotypes to normal in sarcoid lung. Clin Exp Immunol 1997; 108: 105-113.

22 Ziegenhagen MW, Rothe ME, Zissel G, MüllerQuernheim J. Exaggerated $\mathrm{TNF} \alpha$ release of alveolar macrophages in corticosteroid resistant sarcoidosis. Sarcoidosis Vasc Diffuse Lung Dis 2002; 19: 185-190.

23 Drent $M$, van den Berg R, Haenen GR, van den Berg $H$, Wouters EF, Bast A. NF- $\kappa$ B activation in sarcoidosis. Sarcoidosis Vasc Diffuse Lung Dis 2001; 18: 50-56.

24 Rutherford RM, Kehren J, Staedtler F, et al. Functional genomics in sarcoidosis - reduced or increased apoptosis? Swiss Med Wkly 2001; 131: 459-470.

25 Conron M, Bondeson J, Pantelidis $\mathrm{P}$, et al. Alveolar macrophages and $\mathrm{T}$ cells from sarcoid, but not normal lung, are permissive to adenovirus infection and allow analysis of NF- $\mathrm{BB}$-dependent signaling pathways. Am J Respir Cell Mol Biol 2001; 25: 141-149.

26 Adcock IM, Ito K. Molecular mechanisms of corticosteroid actions. Monaldi Arch Chest Dis 2000; 55: 256-266.

27 Selroos O, Sellergren TL. Corticosteroid therapy of pulmonary sarcoidosis. A prospective evaluation of alternate day and daily dosage in stage II disease. Scand J Respir Dis 1979; 60: 215-221.

28 Pinkston P, Saltini C, Muller-Quernheim J, Crystal RG. Corticosteroid therapy suppresses spontaneous interleukin 2 release and spontaneous proliferation of lung $\mathrm{T}$ lymphocytes of patients with active pulmonary sarcoidosis. J Immunol 1987; 139: 755-760.

29 Turner-Warwick M, McAllister W, Lawrence R, Britten A, Haslam PL. Corticosteroid treatment in pulmonary sarcoidosis: do serial lavage lymphocyte counts, serum angiotensin converting enzyme measurements, and gallium-67 scans help management? Thorax 1986; 41: 903-913.

30 James DG, Carstairs LS, Trowell J, Sharma OP. Treatment of sarcoidosis. Report of a controlled therapeutic trial. Lancet 1967; 2: 526-528.

31 Israel HL, Fouts DW, Beggs RA. A controlled trial of prednisone treatment of sarcoidosis. Am Rev Respir Dis 1973; 107: 609-614.

32 Roth I, Ehrke I, Eule H, Weinecke W. First report of a controlled therapeutic trial with prednisolone in pulmonary sarcoidosis. [Erster Bericht über eine kontrollierte klinische Untersuchung zur Prednisolon-Behandlung der thorakalen Sarkoidose]. Z Erkr Atmungsorgane 1975; 142: $49-58$. 
33 Zaki MH, Lyons HA, Leilop L, Huang CT. Corticosteroid therapy in sarcoidosis. A five-year, controlled follow-up study. N Y State J Med 1987; 87: 496-499.

34 Pietinalho A, Tukiainen $\mathrm{P}$, Haahtela $\mathrm{T}$, Persson $\mathrm{T}$, Selroos O, Finnish Pulmonary Sarcoidosis Study Group. Oral prednisolone followed by inhaled budesonide in newly diagnosed pulmonary sarcoidosis: a double-blind, placebo-controlled multicenter study. Chest 1999; 116: 424-431.

35 Pietinalho A, Tukiainen $\mathrm{P}$, Haahtela $\mathrm{T}$, Persson $\mathrm{T}$, Selroos O. Early treatment of stage II sarcoidosis improves 5-year pulmonary function. Chest 2002; 121: 24-31.

36 Paramothayan NS, Lasserson TJ, Jones PW. Corticosteroids for pulmonary sarcoidosis. Cochrane Database Syst Rev 2005; CD001114.

37 Paramothayan S, Jones PW. Corticosteroid therapy in pulmonary sarcoidosis: a systematic review. JAMA 2002; 287: 1301-1307.

38 Gibson GJ, Prescott RJ, Muers MF, et al. British Thoracic Society Sarcoidosis study: effects of long term corticosteroid treatment. Thorax 1996; 51: 238-247.

39 Reich JM. Mortality of intrathoracic sarcoidosis in referral vs population-based settings: influence of stage, ethnicity, and corticosteroid therapy. Chest 2002; 121: 32-39.

40 Selroos O, Lofroos AB, Pietinalho A, Niemisto M, Riska H. Inhaled budesonide for maintenance treatment of pulmonary sarcoidosis. Sarcoidosis 1994; 11: 126-131.

41 Spiteri MA, Newman SP, Clarke SW, Poulter LW. Inhaled corticosteroids can modulate the immunopathogenesis of pulmonary sarcoidosis. Eur Respir J 1989; 2: 218-224.

42 Erkkila S, Froseth B, Hellstrom PE, et al. Inhaled budesonide influences cellular and biochemical abnormalities in pulmonary sarcoidosis. Sarcoidosis 1988; 5: 106-110.

43 Spiteri MA. Inhaled corticosteroids in pulmonary sarcoidosis. Postgrad Med J 1991; 67: 327-329.

44 Milman N, Graudal N, Grode G, Munch E. No effect of high-dose inhaled steroids in pulmonary sarcoidosis: a double-blind, placebo-controlled study. J Intern Med 1994; 236: 285-290.

$45 \mathrm{du}$ Bois RM, Greenhalgh PM, Southcott AM, Johnson NM, Harris TA. Randomized trial of inhaled fluticasone propionate in chronic stable pulmonary sarcoidosis: a pilot study. Eur Respir J 1999; 13: 1345-1350.

46 McGrath D, Wells AU, Desai SR, et al. Efficacy, safety and tolerability of 3M HFA-134a beclomethasone dipropionate in pulmonary sarcoidosis. Am J Respir Crit Care Med 2002; 165: A495.

47 Baughman RP, Iannuzzi MC, Lower EE, et al. Use of fluticasone in acute symptomatic pulmonary sarcoidosis. Sarcoidosis Vasc Diffuse Lung Dis 2002; 19: 198-204.

48 Alberts C, van der Mark TW, Jansen HM. Inhaled budesonide in pulmonary sarcoidosis: a double-blind, placebo-controlled study. Dutch Study Group on Pulmonary Sarcoidosis. Eur Respir J 1995; 8: 682-688.

49 Bechtel JJ, Starr T III, Dantzker DR, Bower JS. Airway hyperreactivity in patients with sarcoidosis. Am Rev Respir Dis 1981; 124: 759-761.

50 Marcias S, Ledda MA, Perra R, Severino C, Rosetti L. Aspecific bronchial hyperreactivity in pulmonary sarcoidosis. Sarcoidosis 1994; 11: 118-122.
51 Shorr AF, Torrington KG, Hnatiuk OW. Endobronchial involvement and airway hyperreactivity in patients with sarcoidosis. Chest 2001; 120: 881-886.

52 Kirsten D. Inhaled steroids for sarcoidosis? Eur Respir J 1995; 8: 679-681.

53 Sharma OP. Vitamin D, calcium, and sarcoidosis. Chest 1996; 109: 535-539.

54 Hoitsma E, Marziniak M, Faber CG, et al. Small fibre neuropathy in sarcoidosis. Lancet 2002; 359: 2085-2086.

55 Papadopoulos KI, Hornblad Y, Liljebladh H, Hallengren B. High frequency of endocrine autoimmunity in patients with sarcoidosis. Eur J Endocrinol 1996; 134: 331-336.

56 Hiraga H, Hiroe M, Iwai K. Guideline for the Diagnosis of Cardiac Sarcoidosis: Study Report on Diffuse Pulmonary Diseases [in Japanese]. Tokyo, Japanese Ministry of Health and Welfare, 1993; pp. 23-24.

57 Yazaki $Y$, Isobe M, Hiroe M, et al. Prognostic determinants of long-term survival in Japanese patients with cardiac sarcoidosis treated with prednisone. Am J Cardiol 2001; 88: 1006-1010.

58 Kato Y, Morimoto S, Uemura A, Hiramitsu S, Ito T, Hishida $H$. Efficacy of corticosteroids in sarcoidosis presenting with atrioventricular block. Sarcoidosis Vasc Diffuse Lung Dis 2003; 20: 133-137.

59 Chiu CZ, Nakatani S, Zhang G, et al. Prevention of left ventricular remodeling by long-term corticosteroid therapy in patients with cardiac sarcoidosis. Am J Cardiol 2005; 95: 143-146.

60 Chapelon-Abric C, de Zuttere D, Duhaut P, et al. Cardiac sarcoidosis: a retrospective study of 41 cases. Medicine (Baltimore) 2004; 83: 315-334.

61 Ishikawa T, Kondoh H, Nakagawa S, Koiwaya Y, Tanaka K. Steroid therapy in cardiac sarcoidosis. Increased left ventricular contractility concomitant with electrocardiographic improvement after prednisolone. Chest 1984; 85: 445-447.

62 Roberts WC, McAllister HA Jr, Ferrans VJ. Sarcoidosis of the heart. A clinicopathologic study of 35 necropsy patients (group 1) and review of 78 previously described necropsy patients (group 11). Am J Med 1977; 63: 86-108.

63 Sharma OP. Neurosarcoidosis: a personal perspective based on the study of 37 patients. Chest 1997; 112: 220-228.

64 Allen RK, Sellars RE, Sandstrom PA. A prospective study of 32 patients with neurosarcoidosis. Sarcoidosis Vasc Diffuse Lung Dis 2003; 20: 118-125.

65 Zajicek JP, Scolding NJ, Foster O, et al. Central nervous system sarcoidosis-diagnosis and management. QJM 1999; 92: 103-117.

66 Ohara K, Judson MA, Baughman RP, Clinical aspects of ocular sarcoidosis. Eur Respir Mon 2005; 10, 32: 188-209.

67 Rothova A, Alberts C, Glasius E, Kijlstra A, Buitenhuis HJ, Breebaart AC. Risk factors for ocular sarcoidosis. Doc Ophthalmol 1989; 72: 287-296.

68 Obenauf CD, Shaw HE, Sydnor CF, Klintworth GK. Sarcoidosis and its ophthalmic manifestations. Am J Ophthalmol 1978; 86: 648-655.

69 Silver MR, Messner LV. Sarcoidosis and its ocular manifestations. J Am Optom Assoc 1994; 65: 321-327.

70 Lynch JP III, McCune WJ. Immunosuppressive and cytotoxic pharmacotherapy for pulmonary disorders. Am J Respir Crit Care Med 1997; 155: 395-420. 
71 Davies D, Curwen MP. Chloroquine in the treatment of sarcoidosis. A report from the Research Committee of the British Tuberculosis Association. Tubercle 1967; 48: 257-272.

72 Baltzan M, Mehta S, Kirkham TH, Cosio MG. Randomized trial of prolonged chloroquine therapy in advanced pulmonary sarcoidosis. Am J Respir Crit Care Med 1999; 160: 192-197.

73 Wyser CP, van Schalkwyk EM, Alheit B, Bardin PG, Joubert JR. Treatment of progressive pulmonary sarcoidosis with cyclosporin A. A randomized controlled trial. Am J Respir Crit Care Med 1997; 156: 1371-1376.

74 Baughman RP, Winget DB, Lower EE. Methotrexate is steroid sparing in acute sarcoidosis: results of a double blind, randomized trial. Sarcoidosis Vasc Diffuse Lung Dis 2000; 17: 60-66.

75 Paramothayan S, Lasserson T, Walters EH. Immunosuppressive and cytotoxic therapy for pulmonary sarcoidosis. Cochrane Database Syst Rev 2003; CD003536.

76 Baughman RP, Lower EE. Leflunomide for chronic sarcoidosis. Sarcoidosis Vasc Diffuse Lung Dis 2004; 21: 43-48.

77 Baughman RP, Lower EE, Therapy for sarcoidosis. Eur Respir Mon 2005; 32: 301-315.

78 Müller-Quernheim J, Kienast K, Held M, Pfeifer S, Costabel U. Treatment of chronic sarcoidosis with an azathioprine/prednisolone regimen. Eur Respir J 1999; 14: 1117-1122.

79 Dev S, McCallum RM, Jaffe GJ. Methotrexate treatment for sarcoid-associated panuveitis. Ophthalmology 1999; 106: 111-118.

80 Hoitsma E, Sharma OP, Neurosarcoidosis. Eur Respir Mon 2005; 32: 164-187.

81 Baughman RP, Judson MA, Teirstein AS, Möller DR, Lower EE. Thalidomide for chronic sarcoidosis. Chest 2002; 122: 227-232.

82 Baughman RP, Lower EE. Infliximab for refractory sarcoidosis. Sarcoidosis Vasc Diffuse Lung Dis 2001; 18: $70-74$.
83 Yee AM, Pochapin MB. Treatment of complicated sarcoidosis with infliximab anti-tumor necrosis factor- $\alpha$ therapy. Ann Intern Med 2001; 135: 27-31.

84 Baughman RP, Bradley DA, Lower EE. Infliximab in chronic ocular inflammation. Int J Clin Pharmacol Ther 2005; 43: 7-11.

85 Baughman RP, Lower EE, Bradley DA, Raymond LA, Kaufman A. Etanercept for refractory ocular sarcoidosis: results of a double-blind randomized trial. Chest 2005; 128: 1062-1047.

86 Utz JP, Limper AH, Kalra S, et al. Etanercept for the treatment of stage II and III progressive pulmonary sarcoidosis. Chest 2003; 124: 177-185.

87 Van den Brande JM, Braat H, van den Brink GR, et al. Infliximab but not etanercept induces apoptosis in lamina propria T-lymphocytes from patients with Crohn's disease. Gastroenterology 2003; 124: 1774-1785.

88 Hunninghake GW, Costabel U, Ando M, et al. ATS/ERS/ WASOG statement on sarcoidosis. Sarcoidosis Vasc Diffuse Lung Dis 1999; 16: 149-173.

89 Costabel U. Sarcoidosis: clinical update. Eur Respir J 2001; 18: Suppl. 32, 56s-68s.

90 James DG. Life-threatening situations in sarcoidosis. Sarcoidosis Vasc Diffuse Lung Dis 1998; 15: 134-139.

91 DeRemee RA. The present status of treatment of pulmonary sarcoidosis: a house divided. Chest 1977; 71: 388-393.

92 Johns CJ, Schonfeld SA, Scott PP, Zachary JB, MacGregor MI. Longitudinal study of chronic sarcoidosis with low-dose maintenance corticosteroid therapy. Outcome and complications. Ann N Y Acad Sci 1986; 465: 702-712.

93 Sharma OP. Pulmonary sarcoidosis: management. J Postgrad Med 2002; 48: 135-141.

94 Conron M, Young C, Beynon HL. Calcium metabolism in sarcoidosis and its clinical implications. Rheumatology (Oxford) 2000; 39: 707-713.

95 Rizzato G. Clinical impact of bone and calcium metabolism changes in sarcoidosis. Thorax 1998; 53: 425-429.

96 Sharma OP. Renal sarcoidosis and hypercalcaemia. Eur Respir Mon 2005; 10, 32: 220-232. 